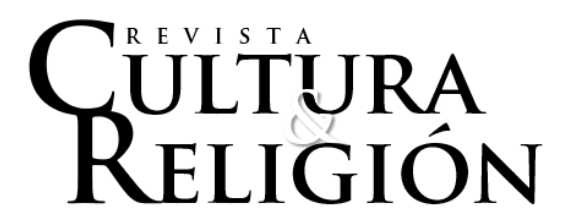

Vol. XIII, N 2 (2019) pp. 52-74

Recibido: 19 de julio, 2018.

Aceptado: 14 de noviembre, 2019

\title{
POLÍTICA SEXUAL Y ACTORES RELIGIOSOS: LA OPOSICIÓN CATÓLICA EN LA ESCENA MEDIÁTICA ARGENTINA $^{1}$
}

\author{
Sexual politics and religious actors: the catholic opposition in the argentine \\ media scene \\ por \\ Candelaria Sgró Ruata* \\ Universidad Nacional de Córdoba, UNC \\ candelariasgro@yahoo.com
}

\begin{abstract}
Resumen
Este trabajo indaga la presencia de actores religiosos conservadores en la escena mediática argentina en un contexto en el que la sexualidad se politiza. Se parte de considerar a los medios de comunicación como uno de los espacios públicos más relevantes para incidir en los debates políticos contemporáneos. Para cumplir con el objetivo de indagación, se planificó una estrategia metodológica de construcción y análisis del corpus que quedó conformado por 105 notas periodísticas publicadas por Clarín y La Nación. El análisis realizado permitió advertir que la jerarquía católica lideró la oposición en la escena mediática argentina.
\end{abstract}

Palabras clave: Politización de la sexualidad, matrimonio igualitario, actores conservadores, prensa gráfica, derechos sexuales y reproductivos.

\begin{abstract}
This work investigates the presence of conservative religious actors in the Argentine press in a context in which sexuality is politicized. The media is assumed as one of the most relevant public spaces to influence contemporary political debates. In order to fulfill the goal of the

\footnotetext{
${ }^{1}$ Este artículo se enmarca en el proyecto "Configuraciones conservadoras: Actores y discursos de oposición en la política sexual argentina", desarrollado en CONICET.

* Doctora en Estudios Sociales de América Latina, Centro de Estudios Avanzados, Universidad Nacional de Córdoba, Argentina (CEA-UNC). Investigadora del Consejo Nacional de Investigaciones Científicas y Técnicas (CONICET), Centro de Investigaciones Jurídicas y Sociales (CIJS-UNC). Profesora de la Facultad de Ciencias de la Comunicación (UNC). ORCID: http://orcid.org/0000-0002-4842-3331
}

Revista Cultura \& Religión Vol. XIII, 2019 Nº 2 (julio-diciembre)

Cómo citar este artículo: Sgró, C. (2019). "Política sexual y actores religiosos: la oposición católica en la escena mediática argentina”. Revista Cultura \& Religión.13(2). pp.52-74. 
investigation, a methodological strategy was planned to construct and analyze the corpus composed by 105 journalistic notes published in the newspapers Clarín and La Nación. The analysis showed that the Catholic hierarchy led the opposition in the Argentine media scene.

Keywords: Politicization of sexuality, same-sex marriage, conservative actors, media press, sexual and reproductive rights

\section{Introducción}

En Argentina, distintas demandas por políticas de sexualidad y reproducción lograron atravesar el debate público impulsadas principalmente por movimientos feministas y por la diversidad sexual. Estos procesos de politización de la sexualidad, en particular desde los noventas de la mano de demandas por la ampliación y reconocimiento de derechos sexuales y reproductivos (DDSSRR), inscriben en el espacio público diferentes cuestionamientos al orden sexual, volviendo visibles al mismo tiempo, las múltiples formas de subordinación y privilegios sostenidas por ese orden. Al politizar la sexualidad, los movimientos feministas y por la diversidad sexual desarticulan las posturas esencialistas y denuncian las jerarquizaciones sobre las que se construye el orden sexual (Vaggione, 2014).

Ahora bien, los avances en políticas de sexualidad y reproducción también vuelven visibles o dan cuenta de la presencia de actores y discursos que se articulan en oposición a estas demandas buscando incidir en el debate político para impedir o revertir sus transformaciones. Como lo señala un importante caudal de estudios, en Argentina como en otros países de América Latina, la Iglesia católica ha sido uno de los principales actores de oposición a las demandas de movimientos feministas y por la diversidad sexual (Vaggione \& Mujica, 2013) y de manera más reciente, algunos sectores de las iglesias evangélicas (Campos Machado, 2013; Jones \& Cunial, 2011; Natividade \& Olivera, 2009). ${ }^{2}$ Asimismo, con especial interés en los últimos años, distintos estudios pusieron de relieve las organizaciones o movimientos civiles, algunos auto-nominados provida o profamilia, alineados al posicionamiento oficial de las jerarquías eclesiales en defensa de un orden sexual fundado en la familia reproductiva/heterosexual y en la vida desde la concepción hasta la muerte natural (Morán Faúndes, 2012; Maier, 2010).

Estas articulaciones han sido pensadas en torno a un nuevo tipo de activismo que antagoniza con los movimientos feministas y por la diversidad sexual desplegando distintas estrategias en contra de DDSSRR. En este sentido, lo religioso/la religión emerge como

\footnotetext{
${ }^{2}$ Brasil, es un ejemplo de la creciente participación evangélica en disputas electorales logrando ingresar al poder parlamentario y la articulación de discursos públicos (Campos Machado, 2013) basados en la cura a la homosexualidad o terapias reparadoras (Natividade \& Olivera, 2009) para confrontar en debates por reconocimiento de derechos.
}

Revista Cultura \& Religión Vol. XIII, 2019 Nº 2 (julio-diciembre)

Cómo citar este artículo: Sgró, C. (2019). "Política sexual y actores religiosos: la oposición católica en la escena mediática argentina”. Revista Cultura \& Religión.13(2). pp.52-74. 
dimensión operante de la política sexual contemporánea, en particular en la región latinoamericana, donde la influencia de la Iglesia católica ${ }^{3}$ sigue siendo central en el sostenimiento de una matriz que controla y jerarquiza la sexualidad definida sólo por su capacidad reproductiva (Vaggione \& Mujica, 2013).

Cuando demandas por DDSSRR ingresan a la agenda parlamentaria, el espacio de lo público se convierte en una usina de voces que se posicionan a favor o en contra de las transformaciones legislativas. En estos momentos singulares, gran parte de la disputa se despliega en la contraposición de concepciones, argumentos y estrategias orientadas a interpelar audiencias más amplias por lo que la posibilidad de expandir los umbrales de visibilidad (y con ellos, los de decibilidad) se vuelve una pieza clave para el debate político. En este sentido, más allá de los ámbitos de influencia capitalizados por los actores/voces que intervienen en las disputas sociales, en sociedades altamente mediatizadas como las nuestras (Asp, 2014), la escena mediática se posiciona como uno de los espacios públicos más relevantes en la pugna por lograr legitimidad y representación.

Por esta razón y en este marco, interesa indagar la presencia pública de actores religiosos cuando ingresan al debate parlamentario iniciativas de reforma legal vinculadas con el reconocimiento de DDSSRR. Precisamente, en este trabajo observamos los actores /voces religiosas que lograron ingresar en la escena mediática argentina en contra de la ley de matrimonio igualitario. Para ello, en primer lugar presentamos lineamientos conceptualesmetodológicos, bases desde las que construimos el corpus de análisis y los procedimientos realizados para la observación del material. En segundo lugar, presentamos un panorama general de los actores/voces religiosas en la escena mediática para, y en tercer lugar, focalizar en aquellos de mayor presencia, vinculados con la religión católica.

\section{Lineamientos conceptuales-metodológicos: El espacio mediático}

Distintos debates por DDSSRR en Latinoamérica pusieron de relieve la importancia del espacio mediático al momento de posicionarse públicamente en contextos signados por sectores en disputa. Con foco en lo mediático o considerándolo como una de las dimensiones del análisis, numerosos trabajos abordaron disputas sobre sexualidad y el espacio público mediático en distintos países de Latinoamérica; por ejemplo, el debate sobre educación sexual en la prensa de Chile (Araujo, 2005), el debate sobre aborto en la prensa de Brasil (Rosado \& Citeli, 2010) entre otros. En Argentina, el tratamiento del debate sobre despenalización del aborto en la prensa gráfica (Rovetto, 2013) o la televisación de imágenes para la construcción de sentidos en contra del aborto (Laudano, 2012), el debate por la ley de

\footnotetext{
${ }^{3}$ Son numerosos los estudios que destacan, desde diferentes enfoques, la influencia de la jerarquía católica en contextos de politización de la sexualidad. Por ejemplo, en México las disputas por despenalización del aborto (Lamas, 2012) o el reconocimiento matrimonial a parejas de mismo sexo (Maier \& Alonso, 2011) o distintas políticas de sexualidad y reproducción en países del Cono Sur (Dides, 2004), entre muchos otros.
}

Revista Cultura \& Religión Vol. XIII, 2019 № 2 (julio-diciembre)

Cómo citar este artículo: Sgró, C. (2019). "Política sexual y actores religiosos: la oposición católica en la escena mediática argentina”. Revista Cultura \& Religión.13(2). pp.52-74. 
educación sexual integral en la prensa nacional (Boccardi, 2008), entre otros estudios. En este sentido, la escena mediática adquiere relevancia particular cuando se intenta difundir una posición o influir sobre los marcos interpretativos vinculados con sexualidad y reproducción (Rosado \& Citeli, 2010). Esto no es menor ya que el ingreso de un tema a la agenda mediática (o por el contrario, la resistencia a ese ingreso) afecta al debate político tanto como los discursos que son puestos en circulación pública en torno a cada temática.

Ahora bien, pensar la escena mediática supone, en cierto modo, una combinación de dimensiones relevantes (por ejemplo, aquellas relacionadas con los actores representados, aquellas relacionadas con los argumentos utilizados, las relacionadas con el espacio o el lugar asignados al tema, entre otras) que demandan, en cada caso, la necesidad de explicitar el enfoque o los presupuestos desde los que se consideran a los medios de comunicación o el espacio mediático (con sus limitaciones y potencialidades).

En esta dirección, consideramos que, en las sociedades actuales, los medios de comunicación se pueden pensar como actores relevantes del juego político (con sus intereses y posicionamientos ideológicos) y como arena política. Así, el mediático es entendido como un espacio al que los actores ingresan (o buscan ingresar) para instalar un asunto, disputar consenso, incidir en la formación de opinión y lograr representación ciudadana. De este modo, consideramos que los actores que disputan y buscan impactar en la política sexual contemporánea reconocen en el espacio mediático, un lugar con fuerte potencial para instalar su posicionamiento. Siguiendo a Calderón (2012), los medios de comunicación necesitan de los conflictos tanto como los conflictos necesitan de los medios en tanto "son espacios públicos en que se reflejan, crean y disputan las relaciones de poder, y donde se reconocen los conflictos entre los actores en pugna" (p.12). Sobre esta perspectiva, en este trabajo, seleccionamos la escena mediática como lugar central "de" y "para" los debates políticosociales contemporáneos. Esto es, no nos centramos en el relato mediático o la puesta en discurso de los medios (Escudero, 2000) sino en los medios de comunicación como uno de los espacios de lo público en los que se despliegan disputas y se visibilizan los actores implicados en ellas.

Así, el enfoque adoptado para el abordaje del material empírico parte de considerar el espacio mediático como un escenario donde circulan (y ganan presencia pública) actores y discursos en disputa y que éstos (actores y discursos) adquieren por la dinámica masmediática un alcance público que sería más difícil de conseguir mediante otras vías. Si se piensa en la potencialidad que tiene la escena mediática, lo anterior cobra especial interés: la presencia en los medios de comunicación se vuelve clave en relación a la difusión de una posición en el espacio público que implica(ría) también una potencialidad para la generación de efectos en el contexto político en el que se inserta.

Revista Cultura \& Religión Vol. XIII, 2019 Nº 2 (julio-diciembre)

Cómo citar este artículo: Sgró, C. (2019). "Política sexual y actores religiosos: la oposición católica en la escena mediática argentina”. Revista Cultura \& Religión.13(2). pp.52-74. 
De esta manera, sin ignorar que los medios de comunicación también pueden analizarse como actores relevantes de las contiendas políticas (con intereses propios en el juego de las disputas), en este trabajo se considera al espacio mediático como uno de los escenarios, "donde los conflictos buscan legitimarse frente a la opinión pública nacional" (Schuster et al., 2006, p. 19).

A nivel metodológico-analítico entonces, la selección de la prensa nacional (como lugar de observación) supone que las disputas políticas también se producen en la escena mediática y en esta dirección es que se vuelve relevante para el abordaje de los actores religiosos que ingresaron al espacio público en oposición al matrimonio igualitario en Argentina. El trabajo analiza la presencia pública de actores en términos de "voces" que intervienen en el debate político. Es decir, el eje no está puesto en las estrategias argumentativas, de difusión o de articulación de estos actores sino en su aparición/ingreso en el espacio público mediatizado.

Para ello, se consideraron dos decisiones analíticas de partida: la primera vinculada con el "momento" de observación, esto es, el debate por la ley 26.618 en Argentina (por el reconocimiento de la institución matrimonial a parejas del mismo sexo) en tanto instancia privilegiada para observar las voces que ingresaron a la escena mediática en una disputa que adquirió una importante movilización social y que colocó a los DDSSRR en el foco de la escena. La segunda, vinculada con el "lugar" de observación considerando el espacio mediático como un espacio fundamental para el debate público y en esta dirección seleccionamos la prensa de circulación nacional para la búsqueda y construcción del corpus analítico.

\section{Criterios de selección del material de observación}

En la prensa de circulación nacional argentina los diarios Clarín y La Nación se posicionan como los dos de mayor tirada (cantidad de ejemplares impresos) del país. Además de sus ediciones diarias en formato papel, estos diarios desarrollan ediciones en formato digital para su acceso vía Internet. A partir de estas consideraciones, se optó por relevar las notas publicadas en los portales de noticias de Clarín y La Nación bajo un criterio de recorte temporal que va desde el mes de marzo al mes de julio de 2010 (específicamente, hasta el 15 de julio, fecha posterior a la sesión en Cámara de Senadores), lapso que se corresponde con la discusión de la ley en el parlamento durante el periodo de sesiones de ese año. Así, el debate por el matrimonio igualitario es tomado en esta presentación como un momento de observación producto de una decisión metodológica; sin embargo, vale mencionar que en el proceso que culmina con la aprobación de la ley 26.618 se combinaron múltiples dimensiones socio políticas las que fueron analizadas (tanto en periodos precedentes como en el contexto de la sanción) por distintos trabajos (Biglieri, 2013; Von Opiela, 2013; Clérico \& Aldao, 2010).

Revista Cultura \& Religión Vol. XIII, 2019 № 2 (julio-diciembre)

Cómo citar este artículo: Sgró, C. (2019). "Política sexual y actores religiosos: la oposición católica en la escena mediática argentina”. Revista Cultura \& Religión.13(2). pp.52-74. 
Para observar los actores religiosos que ingresaron a la prensa en oposición al matrimonio igualitario, diseñamos una estrategia de recolección y de construcción del corpus estructurada en diferentes niveles que se corresponden con ciclos progresivos de lectura del material. En el Cuadro 1, se sintetizan las operaciones diseñadas para la organización de datos cualitativos en tanto instrumento metodológico creado para la realización de este trabajo.

La primera fase (F1) (ver cuadro 1) estuvo dirigida a la recolección del material (notas periodísticas publicadas durante el periodo analizado) mediante la selección de descriptores (palabras clave) de búsqueda. En esta fase se utilizó un criterio amplio de búsqueda del material periodístico que se basó en 15 descriptores vinculados al término sexualidad sobre el que se construyó el que denominamos corpus general. Ahora bien, como señalamos más adelante, en este trabajo se expone una parte de los resultados focalizados en las voces/actores de oposición relacionados con lo religioso/la religión. Por este motivo, describimos la estrategia de recolección y construcción del corpus específico para este objetivo de análisis.

Sobre esta base, la segunda fase (F2) estuvo dedicada a generar operaciones que permitieran recuperar sistemáticamente el material recolectado. Dado que la estrategia de recolección del material surge de un criterio amplio (búsqueda por palabras clave) los diferentes niveles de selección del material implicaron la definición de códigos operativos que nos permitieran el filtrado progresivo de las notas periodísticas (cuadro 1). Para ello, se utilizaron las siguientes operaciones: a) una codificación temática para registrar aquellas notas que tuvieran al matrimonio igualitario- ley 26.618 como tema central o tema tangencial de la nota (F2-A). b) identificación de la aparición de actores (en el material previamente seleccionado) a través de la detección de citas (directas o indirectas) como criterio de demarcación y selección de apariciones (F2-B). c) resultado de las operaciones previas, seleccionamos sólo aquellas notas periodísticas que contienen voces de oposición a la ley e identificamos los actores (individuales o colectivos) que aparecen citados (de manera directa o indirecta) en cada una de las notas periodísticas (F2-C). Esto es, los actores que ingresaron a la escena mediática como "voces" de oposición al matrimonio igualitario.

A partir del trabajo de selección del material conformamos el corpus definitivo de observación ${ }^{4}$ que quedó compuesto por: 105 notas periodísticas (32 en el diario Clarín y 73 en el diario La Nación) que contienen "voces" religiosas de oposición en torno al matrimonio igualitario durante el periodo seleccionado.

\footnotetext{
${ }^{4}$ Es importante destacar que las editoriales de ambos diarios quedaron excluidas del corpus de observación porque éstas demandan un análisis que no es apropiado con el enfoque de este trabajo.
}

Revista Cultura \& Religión Vol. XIII, 2019 № 2 (julio-diciembre)

Cómo citar este artículo: Sgró, C. (2019). "Política sexual y actores religiosos: la oposición católica en la escena mediática argentina”. Revista Cultura \& Religión.13(2). pp.52-74. 
La tercera fase consistió en un procedimiento de categorización que nos permite presentar los actores/voces que ingresaron en la escena mediática argentina (F3-A). El criterio de asignación de categorías responde a la información que cada uno de los diarios presenta en la nota en la que se recupera al actor. Luego, construimos una variable (denominada presencia de intervenciones) para medir la intensidad de su aparición (en términos de presencia de actores agrupados en categorías) en el corpus de trabajo (F3-B) (Ver Tabla 1).

\section{Tabla 1}

Procedimientos para la organización de datos cualitativos

\begin{tabular}{|c|c|c|}
\hline Fases & Procedimientos & Descripción \\
\hline F1 & $\begin{array}{l}\text { Procedimientos de } \\
\text { búsqueda de material }\end{array}$ & $\begin{array}{l}\text { Recolección de las notas periodísticas publicadas durante el } \\
\text { periodo seleccionado (marzo a julio de 2010) con un } \\
\text { criterio de búsqueda por palabras clave (criterio amplio) }\end{array}$ \\
\hline F2-A & $\begin{array}{l}\text { Procedimientos de } \\
\text { codificación del } \\
\text { material }\end{array}$ & $\begin{array}{l}\text { Codificación- temática } \\
\text { Lectura de las notas periodísticas recolectadas } \\
\text { (Fase } 1 \text { - búsqueda por palabras clave). } \\
\text { Identificación y registro de aquellas notas que tienen al } \\
\text { matrimonio igualitario/ley } 26618 \text { como tema central o tema } \\
\text { tangencial de la nota }\end{array}$ \\
\hline F2-B & & $\begin{array}{l}\text { Codificación- Aparición de actores } \\
\text { Identificación de las notas que contienen (en cualquiera de } \\
\text { sus partes) "voces" de actores. Asignar una "voz" implica: } \\
\text { la aparición de citas directas o indirectas (sobre la temática) } \\
\text { y su actor de referencia. }\end{array}$ \\
\hline $\mathrm{F} 2-\mathrm{C}$ & & $\begin{array}{l}\text { Codificación -Actores de oposición } \\
\text { Identificación de los actores (individuales y/o colectivos) } \\
\text { referidos en cada una de las notas periodísticas } \\
\text { (codificación abierta) y selección de aquellas notas que } \\
\text { contienen "voces en oposición" al matrimonio igualitario } \\
\text { (en base a las citas directas o indirectas seleccionadas } \\
\text { previamente). }\end{array}$ \\
\hline F3-A & $\begin{array}{l}\text { procedimientos de } \\
\text { categorización del } \\
\text { material }\end{array}$ & $\begin{array}{l}\text { Procedimiento de clasificación del material textual a partir } \\
\text { de la construcción de una definición conceptual que } \\
\text { delimita la pertenencia (o no) de una unidad a una } \\
\text { categoría (Rodríguez, 1999). Agrupación actores de } \\
\text { oposición en distintas categorías (de manera inductiva). }\end{array}$ \\
\hline
\end{tabular}

Revista Cultura \& Religión Vol. XIII, 2019 № 2 (julio-diciembre)

Cómo citar este artículo: Sgró, C. (2019). "Política sexual y actores religiosos: la oposición católica en la escena mediática argentina”. Revista Cultura \& Religión.13(2). pp.52-74. 
Construcción de la variable presencia de intervenciones con el objetivo de medir la intensidad de la aparición de las categorías en el material seleccionado (notas periodísticas).

Fuente: Elaboración propia

La estrategia de análisis desarrollada permitió delinear el campo de actores de oposición que ingresaron en el debate público y que fueron recuperados por la prensa como "voces" en torno al tema. En otras palabras, el proceso desarrollado nos permitió advertir los actores que ingresaron a la escena mediática como voces "del" debate. El abordaje de la prensa como un lugar de lo público permitió entonces, observar lo que sucede más allá de los espacios que pueden pensarse como predeterminados formalmente para el debate de una reforma legal (como el parlamento).

A continuación, presentamos una de las categorías producto del análisis: la categoría sectores religiosos. De esta forma y a partir de un debate concreto, buscamos reflexionar sobre la presencia de actores/voces religiosas en el campo de oposición delimitado por la escena mediática argentina. En este sentido, es preciso realizar dos señalamientos: en primer lugar, por "presencia" se entiende la aparición de actores en la prensa a partir de la reproducción de la propia voz (por esta razón, utilizamos la denominación actores/voces). En segundo lugar y por último cabe mencionar que, sin ignorar la complejidad que adquiere la dimensión religiosa en particular en conexión con la política sexual contemporánea (Vaggione, 2014), en este trabajo se analizan actores/voces vinculados expresamente con alguna religión desde su identificación pública o, dicho de otro modo, la vinculación con lo religioso se define por la vinculación explicitada en el espacio público.

\section{Presencia de actores (religiosos) en la escena mediática}

El contexto en el que Argentina se convierte en el primer país de América Latina en reconocer a nivel nacional el matrimonio igualitario, estuvo signado por una diversidad de acciones dirigidas a poner de manifiesto, en el espacio público, la oposición al proyecto legislativo: marchas callejeras en distintas ciudades del país (Rabbia \& Iosa, 2011), campañas en redes digitales, participación en audiencias públicas (Sgró Ruata, 2011), entre otras estrategias, ejemplifican la movilización política-social que buscó incidir en el futuro de la ley (Felliti, 2011). En paralelo, además el matrimonio igualitario como tematización ingresó a la agenda de los grandes medios nacionales con una fuerza que no habían logrado otros momentos en los que se debatieron políticas sexuales en Argentina (Peñas \& Vaggione, 2011). Inclusive, a medida que avanzaba la discusión en el Congreso Nacional, el tema fue ingresando con mayor intensidad en los medios (Sgró Ruata \& Rabbia, 2011) y junto a ello, el incremento de la participación de actores/voces en búsqueda por difundir su posición en la escena mediática.

Revista Cultura \& Religión Vol. XIII, 2019 № 2 (julio-diciembre)

Cómo citar este artículo: Sgró, C. (2019). "Política sexual y actores religiosos: la oposición católica en la escena mediática argentina”. Revista Cultura \& Religión.13(2). pp.52-74. 
En este sentido, vale considerar que el acceso a los espacios de difusión masiva en tanto "apoyo material para la circulación de opiniones" (Fraser, 1993, p. 37) permanece como una condición central frente a las posibilidades de ingresar en el debate público. Sin embargo, no "todo el mundo" ingresa a "el gran público" dado que la presencia o aparición en el espacio de los medios masivos implica barreras de accesibilidad operantes,

[...] la política, transformada en un juego donde parece haberse desdibujado el horizonte de los intereses generales en beneficio de los particulares y de la capacidad cada vez mayor de presión sobre las decisiones políticas de grupos de interés, los medios se presentan imaginariamente como el lugar accesible a todos (Fernández Hasan, 2008, p. 285).

Así pues, las posibilidades de acceso a la superficie de los medios masivos como lugar para la difusión y potenciación a audiencias más amplias se encuentran, al menos, condicionadas. Por consiguiente, estas posibilidades inciden en la mayor o menor participación junto a los modos que adquiere esa participación en la escena mediática en un contexto signado por disputas. En otras palabras, el ingreso a la escena mediática como actor/voces en torno a un debate político (en este caso, sobre DDSSRR) supone al menos, haber potenciado la participación $\mathrm{y}$, por tanto, la posibilidad de disputar poder de representación (Reguillo, 2008).

Como mencionamos antes, numerosos trabajos pusieron de relieve la dimensión religiosa cuando se debaten políticas sexuales y reproductivas en especial en relación a la modificación de marcos legales. Tanto jerarquías eclesiales (en particular de la Iglesia católica) como movimientos u organizaciones civiles alineados a los posicionamientos oficiales de las iglesias, se ubican como algunos de los principales antagonistas frente al avance de DDSSRR (Morán Faúndes et al., 2015).

Ahora bien, en un momento concreto de politización ¿qué actores/voces ingresan a los medios? ¿cuál es la fuerza que logra la oposición de estos actores/voces religiosos en la escena mediática? Sobre este marco, indagamos la presencia mediática que consiguieron los actores/voces religiosos en el campo de oposición trazado por los medios de comunicación masivos cuando se debatía el matrimonio igualitario en Argentina. Vale recordar que en este trabajo la "presencia" implica la aparición de actores en la prensa vía la reproducción de su propia voz y por ello utilizamos la denominación actores/voces; asimismo que el vínculo con lo religioso/la religión se define por la vinculación explicitada en el espacio público mediatizado, como señalamos en el apartado metodológico. Así pues, a continuación, se presentan los resultados de esta indagación.

Uno de los interrogantes disparadores de este trabajo giró en torno a la manera en que se delimitó el campo de actores religiosos conservadores en la escena mediática. Con esta pregunta como guía, construimos una categoría que denominamos "sectores religiosos" en la que agrupamos la totalidad de actores/voces (individuales o colectivos) vinculados con

Revista Cultura \& Religión Vol. XIII, 2019 № 2 (julio-diciembre)

Cómo citar este artículo: Sgró, C. (2019). "Política sexual y actores religiosos: la oposición católica en la escena mediática argentina”. Revista Cultura \& Religión.13(2). pp.52-74. 
alguna religión de manera explícita en la prensa. Como señalamos en el apartado metodológico, el criterio de asignación de un actor a una categoría se basó en la información presentada por los diarios respecto al actor citado; de modo que la vinculación con alguna religión se definió por la información referida en el material observado.

Así en el total del corpus (105 notas periodísticas) identificamos 177 intervenciones de actores vinculados con algún sector religioso. Según la identificación religiosa pública, entonces, los actores/voces de oposición que tuvieron presencia mediática pueden distinguirse en: a) católicos, b) evangélicos y c) otros credos (ver gráfico 1).

Entre los primeros (católicos) se encuentra la jerarquía católica a nivel individual (por ejemplo, las intervenciones de distintos obispos y arzobispos) y a nivel colectivo (mediante las intervenciones de la Conferencia Episcopal Argentina). Además, actores/voces de sectores laicos, esto es, agrupaciones u organizaciones conectadas con la estructura organizacional de la Iglesia católica (tal es el caso de las declaraciones de miembros del Departamento de Laicos de la Conferencia Episcopal Argentina). Y finalmente, sectores laicos alineados a la doctrina católica apostólica romana pero que no integran la estructura organizacional de la Iglesia católica (tal es el caso de la Corporación de abogados católicos).

Vemos así que los actores católicos que aparecieron en la prensa con posiciones en contra se nuclean en las voces de la jerarquía católica, los sectores laicos vinculados directamente con la estructura de la iglesia católica y los sectores alineados a sus principios doctrinales. Como muestra el gráfico 1, del total de apariciones de actores/voces en oposición vinculadas con alguna religión: el 86\% en el diario Clarín y el 83\% en el diario La Nación fueron identificadas con el sector católico.

Entre los segundos (evangélicos) se encuentran intervenciones de actores/voces vinculados con la Alianza de Iglesias Evangélicas de Argentina (ACIERA) y de la Federación Confraternidad Evangélica Pentecostal (FECEP). En torno a estas dos entidades se concentraron las voces/actores en oposición en términos de presencia en la escena mediática. En el gráfico 1 se puede observar que los actores/voces vinculadas con los sectores evangélicos representan un $10 \%$ del total de las apariciones registradas en el diario Clarín y un $12 \%$ en el diario La Nación.

Por su parte, en el tercer sector (otros credos), se encuentran actores/voces de oposición vinculados públicamente con diversas religiones como, por ejemplo, las declaraciones de rabinos. Sin embargo, como es posible observar en el gráfico 1, éstas detentan un peso bastante inferior en comparación con los actores/voces vinculadas al catolicismo o las iglesias evangélicas. (3\% y 5\% del total de apariciones registradas en Clarín y La Nación respectivamente) (Ver Figura 1).

Revista Cultura \& Religión Vol. XIII, 2019 № 2 (julio-diciembre)

Cómo citar este artículo: Sgró, C. (2019). "Política sexual y actores religiosos: la oposición católica en la escena mediática argentina”. Revista Cultura \& Religión.13(2). pp.52-74. 


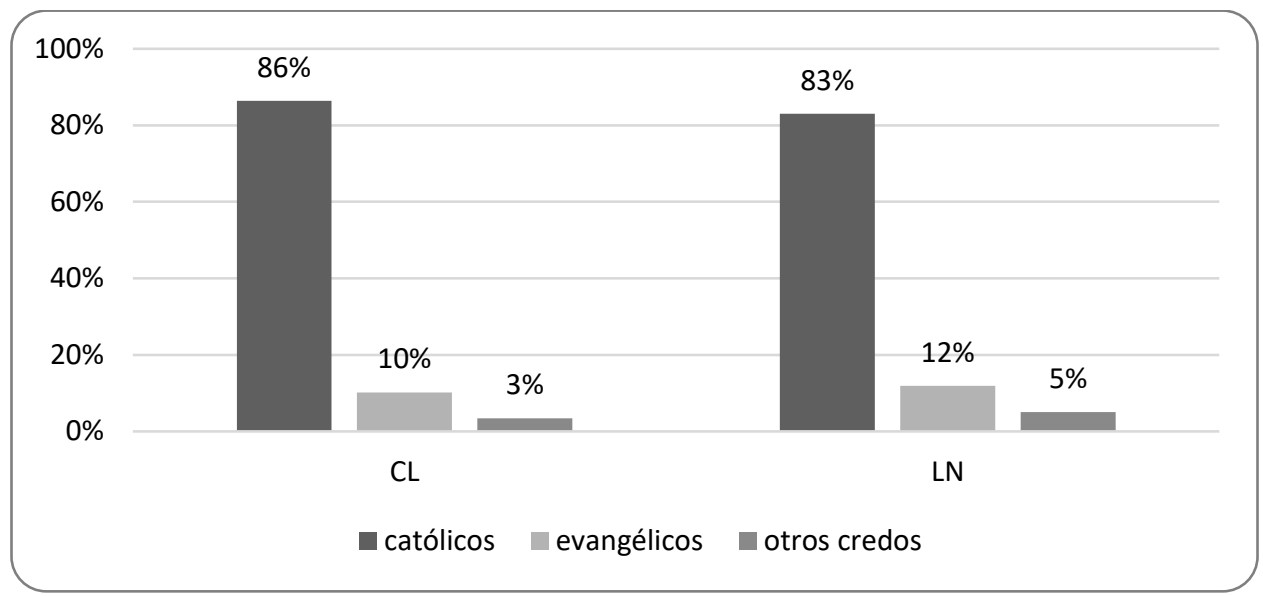

Figura 1: Sectores religiosos en la prensa- diarios Clarín (CL) y La Nación (LN) - según frecuencia de aparición de actores agrupados por identificación religiosa (\%). Fuente: elaboración propia. Datos expresados en porcentajes (\%) en relación al total de apariciones registradas (177 apariciones) en el corpus analizado (105 notas periodísticas).

Es posible sostener que una pluralidad de actores/voces religiosos conservadores tuvieron presencia mediática en el contexto de debate por el matrimonio igualitario. Esta panorámica además muestra que los actores/voces vinculados con el catolicismo conformaron el sector religioso de oposición con mayor incidencia en la escena mediática mientras se debatía el proyecto legislativo en el Congreso de la Nación. Las condiciones que posibilitan este nivel de incidencia de actores católicos en los medios observados requieren otro análisis. De todas maneras, lo que interesa aquí es resaltar que los actores católicos tuvieron, en base a la observación de los datos, una importante incidencia en la escena mediática. A continuación, profundizamos sobre esto.

\section{Actores católicos en foco}

Si ahora concentramos la mirada en el sector católico y distinguimos las intervenciones al interior de este sector en particular, observamos que son las voces de la jerarquía católica las que se destacan significativamente en comparación con otros actores identificados con la religión católica (ver tabla 1 y gráfico 2). Como mencionamos antes, los actores/voces de la jerarquía católica adquirieron presencia mediática a través de diversas declaraciones de obispos, arzobispos y de la reproducción de declaraciones institucionales de la Conferencia Episcopal Argentina (CEA). Además, mediante las declaraciones de organizaciones o agrupaciones vinculadas directamente a la Iglesia católica (sectores laicos) o por su alineamiento explícito con sus principios doctrinales (sectores civiles autoidentificados como católicos).

Revista Cultura \& Religión Vol. XIII, 2019 № 2 (julio-diciembre)

Cómo citar este artículo: Sgró, C. (2019). "Política sexual y actores religiosos: la oposición católica en la escena mediática argentina”. Revista Cultura \& Religión.13(2). pp.52-74. 
Sin detenernos en las particularidades de estas declaraciones, es relevante el modo en que varía la proporción al interior del sector católico entre las voces/ actores de obispos y las de agrupaciones vinculadas con la iglesia. En ambos diarios la proporción es similar: si consideramos Clarín, el $73 \%$ de las voces de oposición católica se vincula con la jerarquía eclesial y el $27 \%$ con organizaciones vinculadas directa o indirectamente a la iglesia; de modo semejante, en el caso de La Nación con el $65 \%$ y el 35\% respectivamente. Esto es, como se observa en el gráfico 2 , los actores/voces de la jerarquía católica se posicionan con un significativo nivel de importancia en la escena mediática en comparación con actores/voces de laicos u organizaciones alineadas a la iglesia. De lo anterior se desprende que la jerarquía católica (principalmente, a través de la voz de sus obispos) se posicionó como uno de los actores/voces más fuertes en oposición al matrimonio igualitario en Argentina, al menos en términos de aparición en la escena mediática (Tabla 2).

\section{Tabla 2}

Categoría sectores católicos- Frecuencia de aparición en la prensa, diarios Clarín (CL) y La Nación ( $L N)$

\begin{tabular}{lcccccc}
\hline \multicolumn{1}{c}{ Sector } & \multicolumn{2}{c}{ Clarín (CL) } & \multicolumn{2}{c}{ La Nación (LN) } & \multicolumn{2}{c}{ Totales } \\
\hline Sectores católicos & $\mathrm{f}$ & $\%$ & $\mathrm{f}$ & $\%$ & $\mathrm{f}$ & $\%$ \\
católica-jerarquía & 37 & $73 \%$ & 65 & $66 \%$ & 102 & $68 \%$ \\
católico-otros & 14 & $27 \%$ & 33 & $34 \%$ & 47 & $32 \%$ \\
Totales & 51 & $100 \%$ & 98 & $100 \%$ & 149 & $100 \%$ \\
\hline
\end{tabular}

Fuente: elaboración propia. Distribución de la categoría sectores católicos sobre el total de apariciones registradas (149 apariciones) en el corpus analizado (105 notas periodísticas). Datos expresados en frecuencia (f) y porcentaje (\%). 


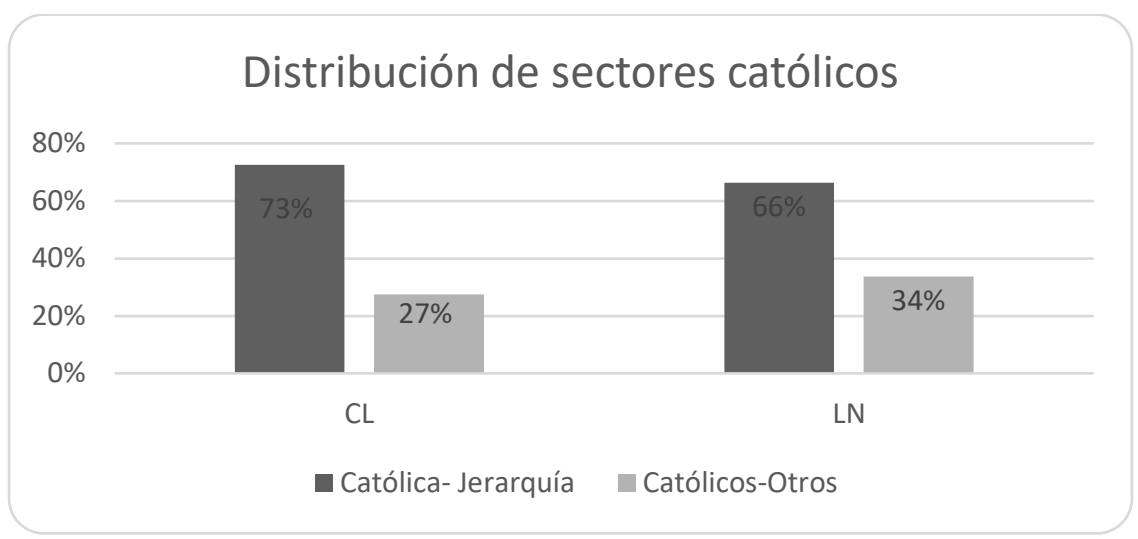

Figura 2: Distribución de la categoría sectores católicos según frecuencia de aparición (\%) en la prensa- diarios Clarín (CL) y La Nación (LN). Fuente: elaboración propia. Datos expresados en porcentajes $(\%)$ en relación al total de apariciones registradas (149apariciones) en el corpus analizado (105 notas periodísticas).

Una de las formas que adquiere la presencia de actores/voces católicas en la escena mediática se produce mediante un formato que podríamos denominar "nota de autor". La nota de autor no necesariamente coincide con alguno de los formatos de clasificación utilizados por el diario (tales como las columnas de opinión). Este formato consiste en artículos o columnas a texto completo firmados por autores identificados con el catolicismo por lo que su característica central es la aparición de actores como voz directa en la prensa con argumentos contrarios a la ley.

A lo largo del periodo observado, fueron publicadas notas de autor pertenecientes tanto a obispos como a integrantes de organizaciones alineadas a la iglesia católica. Por ejemplo, en el mes de mayo se publicó "El orden natural" firmada por E. Sambrizzi (abogado), miembro de la Corporación de Abogados Católicos (en el año 2010 se desempeña como vicepresidente de la entidad). En el mes de junio, "El fin del matrimonio" cuyo autor es G. Cartasso (abogado), presidente del movimiento eclesial FUNDAR; y en el mes de julio, "Legislar como si Dios no existiera" firmada por Monseñor J.E. Lozano (obispo de Gualeguaychú e integrante de la Comisión Episcopal de la Pastoral Social).

De modo que el formato nota de autor junto con la presencia regular (ver gráfico 3) que lograron actores/voces católicos en la escena mediática durante el periodo de discusión parlamentaria puede comprenderse como un indicador de la capacidad que detenta el sector católico para articular o intervenir en lo público mediático en momentos clave de debate político. A esto se suma que la aparición de argumentos en contra de la ley provenientes de 
estos sectores se intensifica en coincidencia con las instancias de votación legislativa (en el mes de mayo, cuando el proyecto adquiere media sanción en la Cámara de Diputados y en el mes de julio cuando se realiza la votación final en la Cámara de Senadores). Aquí interesa rescatar que el nivel de aparición de actores católicos se intensifica en concordancia con los meses en los que se realizaron las votaciones en el Congreso. Aún así, esto no ignora que la mayor intensidad en la aparición de actores pueda estar conectada con la tematización que realizó la prensa u otras dimensiones relevantes que exceden el enfoque de este trabajo (Ver Figura 3).

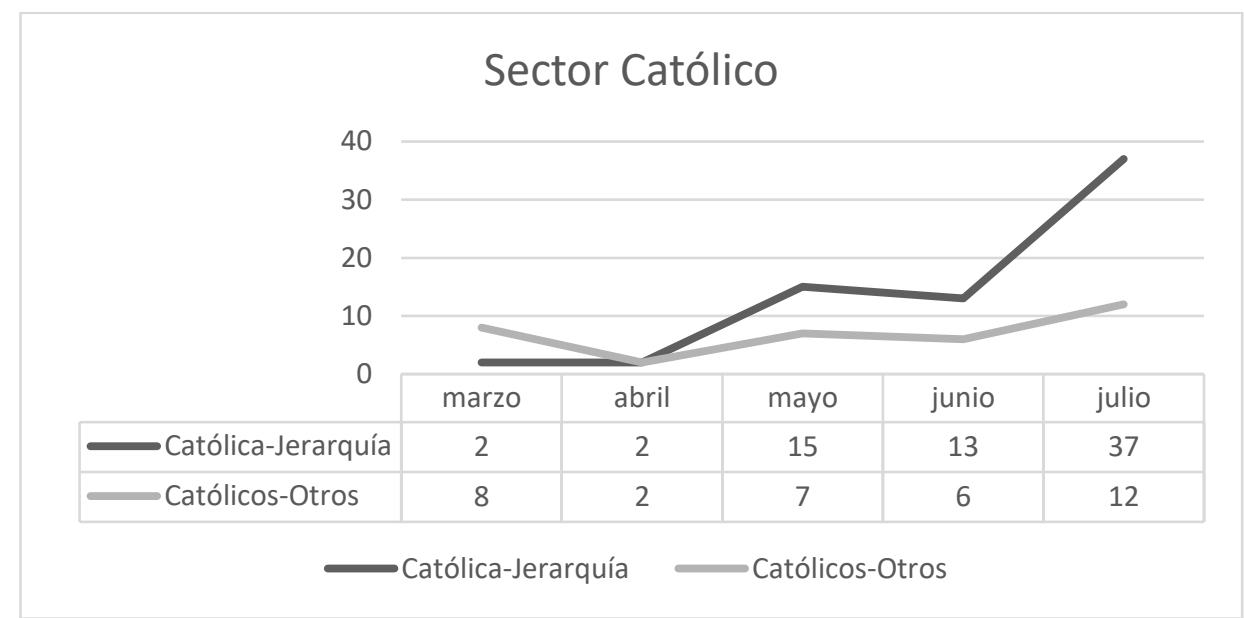

Figura 3: Sector católico (notas de autor) según mes de publicación en la prensa Fuente: elaboración propia. Datos procesados por Notas de Autor identificadas en el total del corpus (105 notas periodísticas) durante el periodo observado (meses de marzo a julio de 2010) pertenecientes a actores identificados con sectores católicos publicadas por la prensa (diarios Clarín y La Nación).

Como mencionamos, la oposición católica en el espacio mediático toma fuerza con el avance del proyecto de ley en el Congreso, en particular luego de la votación en Cámara de Diputados donde el proyecto de ley adquiere media sanción (mes de mayo). En este sentido, es notable el incremento de las intervenciones de la jerarquía católica en el mes de julio que es cuando finalmente la reforma legal se decide en Cámara de Senadores (gráfico 3). El pico de actores/voces católicos en oposición y puntualmente de la jerarquía católica, resulta significativo no sólo en relación al aumento de su presencia en el espacio público mediatizado sino también en vinculación con las tematizaciones en torno a las cuales se produce e intensifica la presencia mediática de la jerarquía católica. Dentro de estas tematizaciones por ejemplo, la interpelación a los legisladores es uno de los puntos temáticos en los que se centraliza la jerarquía católica que ingresa a la escena mediática en oposición a la ley cuando se acerca la votación final en Senadores (mes de julio), retomaremos esto en el apartado siguiente.

Revista Cultura \& Religión Vol. XIII, 2019 № 2 (julio-diciembre)

Cómo citar este artículo: Sgró, C. (2019). "Política sexual y actores religiosos: la oposición católica en la escena mediática argentina”. Revista Cultura \& Religión.13(2). pp.52-74. 
Con todo, el pico de presencia mediática de los actores/voces católicas en oposición puede interpretarse como un embate final, como el intento de revertir lo que parece irreversible en el trámite parlamentario. Dicho de otro modo, la intensificación de la presencia católica en contra de la ley en la escena mediática junto a la tematización centralizada en interpelar a los legisladores es significativa tanto para una mirada que atienda a los medios como actores (habilitantes de esta entrada) como para una mirada que atienda a las estrategias de intervención de la jerarquía católica en el espacio público mediatizado.

Con lo dicho hasta aquí, es posible sostener que una diversidad de actores/voces vinculados con distintas religiones irrumpió en la prensa argentina en oposición al matrimonio igualitario pero la jerarquía católica aparece como centralidad, incluso al interior de la oposición católica mediatizada, y esta particularidad puede comprenderse en clave de un actor que se posiciona (o logró posicionarse) como una voz (autorizada) del debate.

\section{Tematizaciones y presencia la oposición católica en la escena mediática}

En este apartado más que abordar la discursividad desplegada por la oposición católica en la prensa, identificamos algunos núcleos temáticos puntuales en torno a los cuales se conglomeraron los actores/voces católicas en el espacio mediático. En este sentido, la interpelación a legisladores, la convocatoria a la participación y/o acción ciudadana y la definición del contexto en términos de guerra, aparecen como algunos de los núcleos que centralizaron la visibilización de los actores/voces católicas en la escena mediática.

Numerosas declaraciones de obispos y sectores laicos católicos circularon en la prensa buscando interpelar a los legisladores en relación con la actuación o posición que tomarán respecto al devenir de la ley. Asimismo, convocaban a la ciudadanía/pueblo a expresarse y a participar en los distintos eventos que se organizaban en contra de la reforma legal en especial vía la promoción e invitación a las marchas callejeras que se iban realizando en distintas ciudades del país.

El arzobispo platense recordó que el Episcopado exhortó recientemente a las personas a que "no vacilen en expresarse en defensa y promoción de los grandes valores que forjaron nuestra nacionalidad y que constituyen la esperanza de la Patria". Por ello, reclamó que los senadores "no prosigan con la sanción de esta ley que es inicua". (Aguer, Obispo de La Plata, LN- 26/05/10) (De aquí en adelante, el resaltado es nuestro salvo que se indique lo contrario).

"Se exponen a un voto castigo. Mucha gente que se movilizó no va a votar en 2011 a los candidatos que apoyen esta ley.Muchos estarán atentos a quienes se ausenten o se borocoticen", describió el dirigente laico, uno de los organizadores de la concentración que la Iglesia hará el 13 de este mes frente al Congreso. Al día siguiente se definirá la suerte del proyecto en el recinto del Senado. (Carbajales, LN- 05/07/10)

Revista Cultura \& Religión Vol. XIII, 2019 Nº 2 (julio-diciembre)

Cómo citar este artículo: Sgró, C. (2019). "Política sexual y actores religiosos: la oposición católica en la escena mediática argentina”. Revista Cultura \& Religión.13(2). pp.52-74. 
Vale decir brevemente que la posibilidad de modificación legal (donde la institución matrimonial se disocia del requisito de complementariedad de los sexos y el modelo hegemónico de familia se evidencia como construcción sociohistórica), provocó la realización de distintas acciones entre las que se destacó la organización de protestas callejeras por el "matrimonio y la familia" como una forma de ocupación del espacio de lo público por parte del activismo opositor a los DDSSRR. Durante los meses que duró el debate parlamentario, las marchas callejeras se realizaron en distintos puntos del territorio argentino y confluyeron en una gran movilización a nivel nacional convocada un día antes (el 13 de julio) de la votación definitiva de la ley en Capital Federal (Felliti, 2011; Rabbia \& Iosa, 2011). Las marchas callejeras se realizaron en concordancia con otras acciones como distribución de planillas para la recolección de firmas en defensa de la familia dirigidas a demandar a los legisladores su posicionamiento en rechazo a la ley. Más allá de las características, al menos potenciales, que implican ciertos eventos como las protestas callejeras para posicionarse como eventos noticiables, lo que interesa resaltar es que algunos actores/voces católicos irrumpieron en la escena mediática convocando a la movilización ciudadana. Al lograr ingresar en espacios de difusión masiva, las convocatorias potencian su capacidad de expansión y su posibilidad de generar efectos en los diferentes públicos.

El director ejecutivo del DEPLAI, Justo Carbajales, comentó que "será un acto de los ciudadanos con consignas positivas". Y agregó: "No queremos darle un tinte negativo, no es el objetivo de la marcha, sino proponer y promover el matrimonio tal como lo entendemos, entre un varón y una mujer, y expresar el rechazo al proyecto que se aprobó en Diputados" (Carbajales, Departamento de Laicos, CL- 13/07/10)

El prelado platense recordó que "en varias capitales de provincia y en muchas otras ciudades del país se han hecho manifestaciones (en contra del matrimonio gay) que merecen ser destacadas". "Estas manifestaciones continúan, y es necesario que sigan", indicó Aguer, quien invitó a participar de los actos que se realizarán mañana a las 16 en la ciudad de La Plata, y el que se realizará frente al Congreso de la Nación el 13 de julio a las 18. Aguer subrayó que hay que "acompañar ese gran encuentro masivo en la Plaza de los Dos Congresos, donde se concentrará una multitud, no sólo de la Capital Federal, sino también de los municipios cercanos". (Aguer, Obispo de La Plata, LN- 03/07/10)

En el mensaje, Bergoglio llamó a los fieles católicos a asistir masivamente a la marcha convocada por la Iglesia para el martes frente al Congreso, la víspera de la crucial votación en el Senado del proyecto de ley. Bergoglio consideró que de aprobarse la ley "el Estado actuaría erróneamente y entraría en contradicción con sus propios deberes al alterar los principios de la ley natural y del ordenamiento público de la sociedad argentina". (Bergoglio, Arzobispo de Buenos Aires, LN-10/07/10)

Las convocatorias a la movilización ciudadana y la interpelación a los legisladores por parte de los sectores católicos en oposición, adquirió un cariz particular con el ingreso a la escena mediática del Arzobispo de Buenos Aires J. Bergoglio, entonces presidente de la Conferencia Episcopal Argentina y actual Papa de la Iglesia católica. En el momento próximo a la votación final en Cámara de Senadores, la prensa reprodujo una epístola enviada por Bergoglio a las monjas Carmelitas de Buenos Aires, donde invoca al "Señor para que envíe su espíritu a los senadores que han de dar su voto”. Además, para definir el contexto, utilizó

Revista Cultura \& Religión Vol. XIII, 2019 Nº 2 (julio-diciembre)

Cómo citar este artículo: Sgró, C. (2019). "Política sexual y actores religiosos: la oposición católica en la escena mediática argentina”. Revista Cultura \& Religión.13(2). pp.52-74. 
distintas expresiones tales como "movida del padre de la mentira", "envidia del demonio", "tinieblas del terror", entre otras, que fueron recuperadas y difundidas en el espacio mediático. De acuerdo con Jones y Vaggione (2012) los actores católicos utilizaron en general, argumentos seculares en rechazo al matrimonio igualitario pero este desplazamiento hacia lo secular también se manifiesta en el carácter excepcional del uso de argumentaciones religiosas en las declaraciones públicas (p.525). En este sentido, las declaraciones del Arzobispo de Buenos Aires, aparecen en la prensa con una interpelación directa al poder legislativo con un discurso dogmático religioso prácticamente sobre el momento de la votación final en el Senado. Y así, se (re)inscribe en el espacio público una cosmovisión católica que vincula orden legal, orden natural y orden sagrado en un momento clave de debate político.

No seamos ingenuos: no se trata de una simple lucha política; es la pretensión destructiva al plan de Dios», dice el cardenal Jorge Bergoglio, en una carta dirigida a los cuatro monasterios de Buenos Aires, a la que tuvo acceso lanacion.com. (...) "No se trata de un mero proyecto legislativo (éste es sólo el instrumento) sino de una "movida" del padre de la mentira que pretende confundir y engañar a los hijos de Dios", continúa la misiva. (...) En la misma carta, Bergoglio pide a los Monasterios que "clamen al Señor para que envíe su Espíritu a los Senadores" que van a votar el próximo miércoles 14. (...) "Que no lo hagan movidos por el error o por situaciones de coyuntura sino según lo que la ley natural y la ley de Dios les señala", reclama el cardenal. (Bergoglio, Arzobispo de Buenos Aires, LN08/07/10)

El jueves, el cardenal Jorge Bergoglio sostuvo que el proyecto es una "pretensión destructiva al plan de Dios". Lo hizo al llamar a la movilización con la que la Iglesia expresará su rechazo al matrimonio gay el martes frente al Congreso. Esperan que decenas de miles de fieles se sumen para demostrar así que su poder de convocatoria se mantiene intacto. Para eso, se llamó a otros credos. (CL- 11/07/10)

Otro de los eventos vinculados con actores/voces católicas, en particular con la jerarquía católica, fue la reproducción mediática de una definición de la situación en términos de guerra. Precisamente, esta definición ingresó a la escena mediática con las declaraciones de distintos obispos de la Iglesia católica y tomó mayor fuerza durante los Tedeums por el día de la Independencia argentina (el 9 de julio) realizados en diferentes provincias. En este sentido, vale resaltar que la colocación de la situación en términos de guerra toma impulso en la prensa en cercanías a la votación definitiva de la ley y su posible sanción. “(...) El 9 de Julio -sostuvo el prelado- nos encuentra en medio de una guerra» entre el Gobierno, la prensa «que no dice la verdad" y los diferentes credos iglesias en torno a la discusión sobre el matrimonio homosexual. (Monseñor Rodríguez, CL- 09/07/10)

Pareciera que en algunas esferas oficiales, con un fuerte aparato propagandístico e inagotables recursos económicos, se ha puesto en movimiento un nuevo kulturkampf, una guerra cultural contra el sustrato cristiano de nuestro pueblo» (...). (Aguer, Obispo de La Plata, LN- 10/07/10)

Revista Cultura \& Religión Vol. XIII, 2019 Nº 2 (julio-diciembre)

Cómo citar este artículo: Sgró, C. (2019). "Política sexual y actores religiosos: la oposición católica en la escena mediática argentina”. Revista Cultura \& Religión.13(2). pp.52-74. 
La noción de guerra cultural o kulturkampf $\mathrm{f}^{5}$ ingresa en la prensa por la reproducción de declaraciones del obispo de la ciudad de La Plata, H. Aguer. En particular, por la Homilía pronunciada por el obispo en la misa de acción de gracias por el aniversario del 9 de julio, como mencionamos antes. La noción de guerra cultural coloca en el foco una contraposición Iglesia (católica) / Estado e inscribe en el contexto un ánimo persecutorio, donde las políticas estatales busca(ría)n controlar a la iglesia.

Esta noción ingresa con fuerza al espacio mediático e inscribe un campo de confrontación que excede el debate en particular principalmente si se entiende como una de las formas de enmarcar la relación Estado/Iglesia católica en general, es decir, más allá del contexto específico del debate de la ley. En esta línea, ya no se trata sólo de esgrimir argumentos en oposición al matrimonio igualitario sino de intervenir en la definición de la situación en la que las discusiones se producen: inscribe un ánimo persecutorio y la sexualidad como asunto público ingresa como una de las formas persecutorias de la doctrina católica. En esta definición, replicada en la escena mediática, la lógica del enfrentamiento desborda el evento en particular y designa un estadio de situación donde predomina lo anticatólico, el anticlericalismo, pero más aún, los intentos de eliminación de la "cultura cristiana" en general.

Como se trabajó hasta aquí, la oposición católica lideró el campo de la oposición religiosa en los diarios de mayor circulación nacional del país y mantuvo en ellos su presencia regular durante el periodo de discusión parlamentaria del proyecto de ley. Considerando las fuentes de información como actores que suministran datos en su calidad de partes con algún grado de interés respecto al asunto tratado (Aruguete \& Zunino, 2013), la jerarquía de la Iglesia católica se posicionó en y fue reconocida por la prensa bajo esta clave. En definitiva, fue utilizada como fuente informativa central en el debate por el matrimonio igualitario en Argentina.

Así, los datos expuestos permiten conjeturar que la Iglesia católica capitaliza una posición de autoridad en (y para) los medios de circulación masiva de carácter general, es decir, aquellos no necesariamente conectados con audiencias identificadas con lo religioso o

\footnotetext{
${ }^{5}$ La apelación a kulturkampf remite al proceso llevado adelante en Alemania por el Ministro Otto Von Bismarck en los 1870s para excluir a la Iglesia del Estado. El proceso contiene tres elementos centrales, a saber: unificación nacional, gobierno parlamentario y secularización, los que fueron denominados como kulturkampf, también conocido como "lucha de civilizaciones" (Hatfield, 1981). Aunque escapa a lo que venimos trabajando, el ingreso de esta noción en el debate por el matrimonio igualitario se puede relacionar con el intento de incluir en la ley el derecho a la objeción de conciencia tal y como ocurrió en el marco de otras políticas y debates legislativos como educación sexual (Esquivel, 2013). Por lo tanto, en este sentido, vale mencionar que el Vaticano explicita y sostiene, en distintos pronunciamientos, la necesidad de reivindicar el derecho a la objeción de conciencia como mecanismo de oposición frente a la sanción o aplicación de leyes vinculadas con aborto, eutanasia (Evangelium Vitae, Juan Pablo II, 1995) o matrimonio entre personas del mismo sexo (Consideraciones, Congregación para la doctrina de la Fe, 2003).
}

Revista Cultura \& Religión Vol. XIII, 2019 № 2 (julio-diciembre)

Cómo citar este artículo: Sgró, C. (2019). "Política sexual y actores religiosos: la oposición católica en la escena mediática argentina”. Revista Cultura \& Religión.13(2). pp.52-74. 
la religión cuando la sexualidad se convierte en un asunto de debate público. La cobertura mediática de discursos pronunciados por obispos en distintas situaciones como los Tedeums o de documentos publicados en los medios propios de difusión de la Iglesia católica (como los boletines del Arzobispado de Buenos Aires o las notas de la agencia católica de noticias AICA) podrían leerse en la misma línea. En este sentido, es válido recuperar siguiendo a Esquivel (2009) que por ejemplo, algunas prácticas como las convocatorias al Tedeum oficial mantienen su permanencia en el tiempo (aún sin tener prescripción normativa) arraigadas en la cultura política y por tanto, revelando el protagonismo de la Iglesia católica en lo público. Este protagonismo así, también puede observar su correlato en la escena mediática: en calidad de fuente informativa, la jerarquía católica lideró el campo de oposición en la prensa nacional con una presencia principalmente nucleada en torno a la demanda al poder legislativo por el rechazo a la ampliación y reconocimiento de DDSSRR.

\section{Conclusiones}

En los distintos contextos sociopolíticos en los que se producen demandas por la legalización del aborto, la educación sexual, el reconocimiento del matrimonio de parejas del mismo sexo, entre otras, emerge un activismo conservador que articula y renueva sus estrategias (discursos y acciones) en defensa de un orden sexual-moral que entienden como amenazado. Así, consideramos que los momentos de debate por DDSSRR potencian la legibilidad del campo de disputas, exponen la diversidad de actores que buscan ingresar en el espacio público para inscribir allí su posición e intervenir en la definición de los asuntos comunes. Es el debate mismo, en tanto "posibilidad" de transformación de los marcos legales, el que evidencia la movilización de actores y voces contrarias al avance de políticas de sexualidad y reproducción.

Bajo esta premisa, observamos los actores/ voces religiosas que ingresaron a la escena mediática argentina en oposición al matrimonio igualitario. El propósito principal fue presentar el resultado de un relevamiento sistemático de datos empíricos fundado en la construcción de una estrategia de observación de un contexto sociopolítico concreto. A partir de esta estrategia, dimos cuenta de la presencia de la oposición religiosa en la escena mediática argentina definiendo esa presencia en relación a las apariciones, esto es, cuando la palabra del propio actor (individual o colectivo) es retomada, reproducida como "voz" en la prensa.

En esta dirección, vimos que actores vinculados con distintos sectores religiosos ingresaron al espacio mediático con manifestaciones en contra del matrimonio igualitario. Sin embargo, fueron los católicos los que se posicionaron como prioritarios: ingresaron a la escena mediática tanto por las voces de la jerarquía eclesial como por las voces de organizaciones de laicos y civiles (auto-identificadas como) católicos.

Revista Cultura \& Religión Vol. XIII, 2019 № 2 (julio-diciembre)

Cómo citar este artículo: Sgró, C. (2019). "Política sexual y actores religiosos: la oposición católica en la escena mediática argentina”. Revista Cultura \& Religión.13(2). pp.52-74. 
A esta significativa presencia de la oposición católica en la prensa además se agrega que son las voces de la jerarquía católica las que adquirieron una visibilidad particular. En este sentido, distintas lecturas interpretativas y vías se podrían abrir para analizar esta particularidad. Este protagonismo de la jerarquía católica, principalmente de sus obispos, puede estar vinculado tanto con las estrategias de difusión que despliegan para incidir en los medios; la estructura organizacional de la iglesia en el país (presencia orgánica de la institución en el territorio); las estrategias discursivas (argumentos religiosos y seculares); o la permeabilidad de las concepciones católicas en la cultura, entre otras dimensiones que podrían ser indagadas.

En función de lo presentado en este trabajo, lo que nos interesa resaltar es que poniendo en foco un momento de politización de la sexualidad de la mano de una disputa por DDSSRR, actores vinculados con lo religioso/la religión intensificaron su participación política para influir en el debate y afectar el devenir del proyecto de ley. Específicamente observamos que la jerarquía católica lideró el campo de oposición religiosa en uno de los espacios más relevantes de visibilización del debate público en nuestras democracias contemporáneas, la escena mediática, como actor y voz reconocida para disputar los marcos normativos del Estado.

Una instancia en la que ingresan a agenda pública demandas por la ampliación y reconocimientos de derechos, no sólo visibiliza aquello que busca transformar sino aquello que lo resiste. Este activismo no es un fenómeno novedoso ni reciente aunque algunas de sus características se transformaron recreando sus formas de participación e injerencia en el espacio público. Como lo vienen poniendo en evidencia algunos trabajos (Esquivel \& Vaggione, 2015) esto exige discusiones que amplíen las dimensiones y las implicancias que tiene para pensar la política sexual y sus giros junto con la necesaria complejización de los vínculos religión, política y sexualidad especialmente en las escenas democráticas actuales.

\section{Referencias}

Araujo, K. (2005). "Sobre ruidos y nueces: debates chilenos en torno a la sexualidad". Iberoamericana América Latina-España y Portugal, 18(5). pp.109-125.

Aruguete, N. \& Zunino, E. (2013)."Diario Clarín y sus fuentes de información. Un estudio de caso". Íconos. Revista de Ciencias Sociales, 46. pp. 15-31

Asp, K. (2014). "Mediatization: rethinking the question of media power". En Mediatization of Communication. (pp. 349-373). K. Lundby (ed.). Berlin: De Gruyter-Mouton.

Bergoglio, J. (2010). “A las monjas carmelitas de Buenos Aires”. Boletín Eclesiástico del Arzobispado de Buenos Aires. 159, Año LII, p. 229

Biglieri, P. (2013). "Emancipaciones. Acerca de la aprobación de la ley del matrimonio igualitario en Argentina". Íconos, Revista de Ciencias Sociales, 46. pp.145-160.

Boccardi, F. (2008). "Educación sexual y perspectiva de género. Un análisis de los debates

Revista Cultura \& Religión Vol. XIII, 2019 Nº 2 (julio-diciembre)

Cómo citar este artículo: Sgró, C. (2019). "Política sexual y actores religiosos: la oposición católica en la escena mediática argentina”. Revista Cultura \& Religión.13(2). pp.52-74. 
sobre la ley de Educación Sexual Integral en la Argentina". Perspectivas de la Comunicación, 1(2). pp. 48-58.

Calderón, F. (2012). "Diez Tesis sobre el conflicto social en América Latina". Revista Cepal, 107. pp. 7-30.

Campos Machado, M. (2013). "Discursos pentecostais em torno do aborto e da homossexualidade na sociedade brasileira". Revista Cultura \& Religión, 7(2). pp.4868.

Clerico, L. \& Aldao, M. (coords.). (2010). Matrimonio igualitario. Perspectivas políticas y jurídicas. Buenos Aires: Eudeba.

Congregación para la Doctrina de la Fe (2003). "Consideraciones acerca de los proyectos de reconocimiento legal de las uniones entre personas homosexuales". Consultado el 2 de septiembre de 2013:

http://www.vatican.va/roman_curia/congregations/cfaith/documents/rc_con_cfaith_ doc_20030731_homosexual-unions_sp.html

Dides, C. (comp.) (2004). Diálogos Sur-Sur sobre religión, derechos y salud sexual y reproductiva: los casos de Argentina, Colombia, Chile y Perú. Santiago de Chile: Universidad Academia de Humanismo Cristiano- Programa de Estudios de Género y Sociedad PROGÉNERO.

Escudero, L. (2000). "Puente del alma: la emergencia de la subjetividad en el escenario mediático". Cuadernos de Información y Comunicación, 5. pp. 79-97.

Esquivel, J. (2013)."Narrativas religiosas y políticas en la disputa por la educación sexual en Argentina". Revista Cultura \& Religión, 7(1). pp.140-163.

Esquivel, J. (2015). "Cultura política y poder eclesiástico". Archives de sciences sociales des religions, Núm. 146, abril/junio 2009, consultado el 3 de abril de 2017 (http://assr.revues.org/21217).

Esquivel, J. \& Vaggione, J. (dirs.) (2015). Permeabilidades activas. Religión, política y sexualidad en la Argentina democrática. Buenos Aires: Biblos.

Felliti, K. (2011). "Estrategias del activismo conservador católico conservador frente al aborto y el matrimonio igualitario en la Argentina". Sociedad y Religión, 34-35(21). . pp. 92-122.

Fernández Hasan, V. (2008). "Una lectura feminista acerca del tratamiento de los derechos de las mujeres en la prensa argentina" Intervenciones sobre ciudadanía de mujeres, política y memoria (pp. 281-306). Ciriza, A. (coord.) Buenos Aires: Feminaria.

Fraser, N. (1993). "Repensar el ámbito público: una contribución a la crítica de la democracia realmente existente". Debate Feminista. 7. pp.23-58.

Hatfield, D. (1981). "Kulturkampf: The Relationship of Church and State and the Failure of German Political Reform". Journal of Church and State, 3(23) pp. 465-484.

Jones, D. \& Cunial, S. (2011). "Evangélicos contra el «matrimonio homosexual» en Argentina: el activismo político de la federación Alianza Cristiana de Iglesias Evangélicas de la República Argentina (ACIERA) "Actores y discursos conservadores en los debates sobre sexualidad y reproducción en Argentina. (pp.

Revista Cultura \& Religión Vol. XIII, 2019 № 2 (julio-diciembre)

Cómo citar este artículo: Sgró, C. (2019). "Política sexual y actores religiosos: la oposición católica en la escena mediática argentina”. Revista Cultura \& Religión.13(2). pp.52-74. 
199-230). Peñas, A. \& Vaggione, J. (comps.). Córdoba: Ferreyra- CDD/UE.

Jones, D. \& Vaggione, J. (2012). "Los vínculos entre religión y política a la luz del debate sobre matrimonio para parejas del mismo sexo en Argentina". Civitas, Porto Alegre, 3 (12). pp. 522-537.

Juan Pablo II. (1995). "Evangelium Vitae". Consultado el 2 de septiembre de 2013: http://w2.vatican.va/content/john-paul-ii/es/encyclicals/documents/hf_jpii_enc_25031995_evangelium-vitae.html

Lamas, M. (2012). "Mujeres, aborto e Iglesia católica". Revista del Colegio de San Luis,.3 (3). pp. 42-67.

Laudano, C. (2012). "Reflexiones en torno a las imágenes fetales en la esfera pública y la noción de vida en los discursos contrarios a la legalización del aborto". Temas de Mujeres,.8(8). pp. 57-68.

Maier, E. (2010). "Discursos, actores y estrategias en la disputa por el significado de la vida y los derechos reproductivos". Región y Sociedad, 22(49). pp. 201-238.

Maier, E. \& Alonso, G. (2011)."Sexo y cultura: disputando el significado del matrimonio y la familia". La Ventana, 4(33). pp. 117-150.

Morán Faúndes, J. (2012). "El activismo católico conservador y los discursos científicos sobre sexualidad: cartografía de una ciencia heterosexual". Sociedad y religión, 22(37) . pp. 167-205.

Morán Faúndes, J.M., Peñas Defago, M.A., Monte, M.E. \& Sgró Ruata, M.C. (2015). "Sociedad civil y sexualidad: las ONG autodenominadas provida". En Permeabilidades activas. Religión, política y sexualidad en la Argentina democrática (pp. 35-54). Esquivel, J.C. \& Vaggione, J.M. (dirs.). Buenos Aires: Biblos.

Natividade, M. \& Oliveira, L. (2009). "Sexualidades ameaçadoras: religião e homofobia(s) em discursos evangélicos conservadores". Sexualidad, Salud y Sociedad, 2. pp. 121161.

Peñas Defago, M., \& Vaggione, J. (comps.). (2011). Actores y discursos conservadores en los debates sobre sexualidad y reproducción en Argentina. Córdoba: Ferreyra/CDD/UE.

Rabbia, H. \& Iosa, T. (2011). "Plazas multicolores, calles naranjas. La agenda del matrimonio entre parejas del mismo sexo en el activismo LGTB cordobés y la oposición religiosa organizada". En El debate sobre matrimonio igualitario en Córdoba. Actores, estrategias y discursos (pp. 33-74). Córdoba: Ferreyra.

Reguillo, R. (2008) "Saber y poder de representación: la(s) disputa(s) por el espacio interpretativo". Comunicación y Sociedad, 9. pp. 11 - 33.

Rosado Nunes, M. \& Citeli, M. (2010). "Religiões na esfera pública: Estratégias institucionais de intervenção- Igreja Católica no Brasil". En El activismo religioso conservador en Latinoamérica. (pp. 19-45). Vaggione, J. (comp.). Córdoba: Ferreyra.

Rovetto, F. (2013). "El debate parlamentario sobre el proyecto de despenalización del aborto en la prensa gráfica argentina. Análisis de la representación de "un día histórico"". Polémicas feministas, 2. pp. 45-59.

Revista Cultura \& Religión Vol. XIII, 2019 № 2 (julio-diciembre)

Cómo citar este artículo: Sgró, C. (2019). "Política sexual y actores religiosos: la oposición católica en la escena mediática argentina”. Revista Cultura \& Religión.13(2). pp.52-74. 
Schuster, F.; Pérez, G.; Pereyra, S.; Armesto, M.r; Armelino, M.; García, A.; Natalucci, A.; Vázquez, M.; Zipcioglu, P. (2006). Transformaciones de la protesta social en Argentina 1989-2003. Buenos Aires: Instituto de Investigaciones Gino Germani, UBA.

Sgró Ruata, M.C. \& Rabbia, H. (2011). "El debate sobre matrimonio igualitario en el espacio público argentino: Escena mediática, actores". En Actores y discursos conservadores en los debates sobre sexualidad y reproducción en Argentina. (pp. 91-126). Peñas, A. \& Vaggione, J. (comps.). Córdoba: Ferreyra- CDD/UE.

Sgró Ruata, M.C. (2011). "Matrimonio entre personas del mismo sexo. Estrategias político discursivas de oposición en la audiencia pública de Córdoba". En El debate sobre matrimonio igualitario en Córdoba. Actores, estrategias y discursos (pp. 179-231). Sgró Ruata, M.C, Rabbia, H., Iosa,T., Manzo, M., Campana,M. \& Morán Faúndes, J.M. Córdoba: Ferreyra.

Vaggione, J. \& Mujica, J. (2013). (comps.).Conservadurismos, religión y política. Perspectivas de investigación en América Latina. Córdoba: Ferreyra.

Vaggione, J. (2014). "La politización de la sexualidad y los sentidos de lo religioso". Sociedad y Religión, 42(24). pp. 209-226

Von Opiela, C. (2013). "Una mirada sobre el matrimonio igualitario en Argentina y en el mundo". Población, 10(6). pp. 101-109. 